\title{
El reto de formar lectores y escritores desde la infancia: una realidad que va más allá del aula
}

\author{
Emilse Carolina Cifuentes Cetina ${ }^{1}$ \\ Corporación Universitaria Minuto de Dios - Bogotá, Colombia \\ emicaromix@gmail.com \\ Johanna González Aguilera² \\ Corporación Universitaria Minuto de Dios - Bogotá, Colombia \\ johanitagonzalez14@hotmail.com \\ Deivis Solangel Morales Reinoso ${ }^{3}$ \\ Corporación Universitaria Minuto de Dios - Bogotá, Colombia \\ Solangel.solangel.morales@gmail.com
}

1 Estudiante de la Licenciatura en Pedagogía Infantil.

2 Estudiante de la Licenciatura en Pedagogía Infantil.

3 Estudiante de la Licenciatura en Pedagogía Infantil. 


\title{
El reto de formar lectores y escritores desde la infancia: una realidad que va más allá del aula
}

\section{Resumen}

A lo largo de la historia, se ha podido observar que el proceso lector-escritor de los niños(as) ha estado enmarcado por la autoridad y la rutina, por tal razón en muchos casos, el proceso ha perdido tanto su valor como su esencia, dejando de lado los intereses de los niños(as) persistiendo en los de los adultos, para quienes en muchas ocasiones, la escritura y la lectura no van más allá de la codificación y decodificación. De esta forma, se reconoce la lectura y la escritura como una tarea ardua, en la que interactúan niños(as) y adultos, y en donde según esta interacción varían los procesos y el desarrollo de habilidades de lectura y escritura. El presente artículo intenta dar a conocer algunos conceptos que tienen los adultos acerca de la lectura y la escritura, para luego analizarlos a la luz de la realidad de los niños(as), a partir del uso que dan a estas herramientas en su cotidianidad, y así generar más información en cuanto a cuál es la posición del docente frente a la formación de lectores y escritores para la vida.

Palabras clave: Lectura, escritura, infancia, rol docente, aprendizaje, contexto.

\section{The challenge of being readers and writers from childhood "a reality that goes beyond the classroom"}

\begin{abstract}
Throughout history it has been observed that the process reader and writer of children has been framed by the authority and routine and in many cases it has lost both its value and its essence, leaving aside the interests of children, the adult persisting for writing and reading not go beyond the encoding and decoding process. So learning to be reading and writing a difficult task, this article seeks to highlight some concepts that have reading and writing and then analyzed in the light of the reality of children and use to give these tools in your everyday life, without neglecting teaching position in front of his responsibility in the formation of readers and writers for life.
\end{abstract}

Keywords: Reading, Writing, Children, Role of Teachers, Learning, Context

\section{0 reto de formar leitores e escritores desde a infância "uma realidade que vai mais longe do que a aula"}

\section{Resumo}

Ao longo da história é possível observar que o processo de leitura e escrita dos meninos(as) foi caracterizado pela autoridade e a rutina, razão pela qual em vários casos o processo perdeu seu valor e sua essência, deixando do lado os interesses dos meninos(as) e impondo os do adulto, para quem, na maioria das vezes, o processo de leitura e escrita não passa da codificação e decodificação. Deste modo, são reconhecidas a leitura e a escritura como tarefas difíceis, nas quais interagem meninos(as) e adultos, e é percebido que dessa relação dependem os processos e o desenvolvimento das faculdades de leitura e escrita. O presente artigo tenta apresentar alguns conceitos que possuem os adultos sobre a leitura e a escrita para, depois, estudá-los tendo em conta a realidade dos meninos(as) e o uso que eles dão a essas ferramentas em sua vida cotidiana, a fim de gerar uma análise maior sobre a posição do docente frente à responsabilidade na formação de leitores e escritores para a vida.

Palavras chave: Leitura, escrita, infância, papel do docente, aprendizagem, contexto. 
El reto de formar lectores y escritores desde la infancia: una realidad que va más allá del aula | Emilse Carolina Cifuentes Cetina | Johanna González Aguilera | Deivis Solangel Morales Reinoso |

Si hay algo que vuele lejos en el mundo es la palabra, literalmente vuela, porque el sonido que lanzamos al viento se monta en el aire y va de mi boca al oído tuyo, donde se cuela misteriosamente para tocar otros miles de palabras que duermen en tu cerebro vistiendo pensamientos, adornando recuerdos, descifrando olores y sabores, tacto, deseos...Luego tomas ese pájaro inquieto que movió emociones, que despertó otras palabras dormidas en la profunda intimidad y vuelves a reconstruir mi palabra para enviarla con la tuya al viento, rumbo a otro corazón y a otro oído.

Francisco Cajiao

El presente artículo tiene como principal objetivo proponer una serie de alternativas enfocadas a fortalecer el proceso lector-escritor en la infancia, para ello enunciaremos algunos de los conceptos pre-establecidos que se tienen en cuanto a la lectura y la escritura, los cuales en muchos casos no permiten el desarrollo de estos procesos en los niños(as) y al contrario los limita y les genera dificultades y desmotivación. En segunda instancia, haremos un análisis teórico en relación con las realidades y motivaciones que los niños(as) manifiestan en cuanto al desarrollo de estas habilidades. Y para concluir, plantearemos cual debería ser el rol y el compromiso que el pedagogo infantil debería asumir para lograr la formación de lectores y escritores en el mundo actual.

\section{La lectura como proceso de decodificación}

Tratar de definir el proceso de lectura no es una tarea fácil, por un lado, se cree que el niño(a) que realiza una lectura de corrido es un buen lector, es decir, logra una decodificación al emitir los sonidos correspondientes a cada letra para formar palabras y oraciones que hacen parte de en un texto, de esta manera se logra dar a conocer un mensaje o acontecimiento. Desde este punto de vista, se estaría relacionando la lectura únicamente con el sistema de representación y no con los sentidos que se le pueden dar a una lectura dentro de una cultura y el buen uso que se da al lenguaje para interpretar e inferir acerca de un texto que se tiene a la mano. Solo así, el niño(a) puede lograr una lectura completa, que lo acerque a sus saberes previos y a la intención comunicativa del autor, y tener de este modo una mejor comprensión.

La lectura va más allá de la simple decodificación, debe buscar dar significado y valor a la cultura y a los diferentes contextos en que los niños(as) se encuentran inmersos, debe ser variada y enriquecida a través del reconocimiento de material impreso (vallas publicitarias, revistas, tarjetas, listas, recetas, cuentos, cartas, manuales, etc.) con un sentido para el niño(a), pues el uso de estos materiales lo 
vivencia en su cotidianidad y no debe ser algo impuesto por el adulto ni mucho menos para alcanzar su aprobación. Se debe guiar al niño hacia la riqueza literaria, procurando alejarlo de los medios distractores y muchas veces dañinos, que en la mayoría de los casos lo conducen a perder el interés por los libros:

El niño de hoy, el público infantil se siente cada vez más poco estimulado a la lectura, debido a la televisión -entre otros vehículos de masa- que fuera de causar alienación, perjudica el desempeño y la creatividad del niño (Oliveira,1994, p. 11).

Debido a lo anterior, es muy importante que el docente tenga una mente abierta al cambio, para que pueda implementar nuevas técnicas para el aprendizaje de la lectura, ya que ésta, en la actualidad, se debe desarrollar también a través de los avances tecnológicos, para poder afrontar este reto de formar lectores para la vida y no para la escuela o para el aula de clase únicamente.

\section{La lectura "una realidad del niño(a)"}

Es preciso resaltar que la lectura, desde la visión del infante, puede llegar a convertirse en una experiencia significativa, que parte de la necesidad y de la motivación. La lectura para el niño es la oportunidad de crear y recrear sus realidades, como también las de los demás a través de la palabra, es la oportunidad de construir nuevos mundos de fantasía y magia en los que la mayoría de veces, el protagonista es él, el héroe y vencedor es él. Nada es imposible para el niño(a), a través de la lectura puede lograrlo todo, solucionarlo todo y mejorarlo todo. La lectura se puede hacer a viva voz o de manera privada o silenciosa:

La lectura de los niños se trata del acto individual, privado, silencioso o "ruidoso", que hacen los niños cuando se enfrentan solos a los textos y los leen a su manera. Aquí, no debe entenderse la lectura como una decodificación pues de la misma forma que pasa con la escritura, la lectura tiene una historia previa y en ella encontramos formas distintas de lectura, como lo son, por ejemplo, la interpretación de indicios que se suceden fundamentalmente en torno a los libros con imágenes, o a las exploraciones que hacen los bebés de los libros en las bebe tecas. Todas ellas son auténticas modalidades de lectura en la primera infancia, que pasan aún cuando los niños y niñas sean bebés.

La lectura hacia, de y con los niños y niñas del mayor número de relatos culturales se constituye sin duda en otro de los pilares básicos y fundamentales en el desarrollo del lenguaje escrito (Negret, 2005, p. 25).

No se puede olvidar que el niño(a) está inmerso(a) en una cultura desde su nacimiento y aún un poco antes, desde el mismo instante en que la madre le canta al niño(a) estando en su vientre, desde allí empieza a nutrirse el amor por la lectura:

Además de los cantos, rimas y retahílas, dichos y leyendas que circulan en el mundo al que llega el niño al nacer, la cultura actual está poblada de un inmenso acervo 
El reto de formar lectores y escritores desde la infancia: una realidad que va más allá del aula | Emilse Carolina Cifuentes Cetina | Johanna González Aguilera | Deivis Solangel Morales Reinoso |

literario. Es crucial, entonces, en la primera infancia, que los niños tengan acceso en la cultura de su época, a las formas escritas, literarias en sentido amplio, a las que no se puede llegar espontáneamente sino como resultado de acciones efectivas de las instituciones educadoras y de la cultura (Negret, 2005, p.24).

\section{Escritura como proceso de codificación}

La escritura considerada como concepto indeterminado, hace referencia a los puntos de vista que de ella se tienen, de este modo, para algunos la escritura es vista como el proceso de codificación escrito, para otros tiene que ver con las bellas formas que se tienen para escribir y para muchos otros es lograr la copia perfecta de un referente escrito que es dado al niño(a) casi siempre por un adulto:

Tradicionalmente hemos pensado que la capacidad de hacer composiciones escritas proviene de aplicar métodos y técnicas definidas. Muchos títulos de libros y de cursos dan testimonio de esta idea, y la identificación de los subprocesos mencionados antes parecería darle fundamento. No obstante, un sujeto presta atención a las técnicas y es susceptible a los métodos, sólo en la medida en que tiene intereses. Y el interés es lo único que no puede enseñarse y, no obstante, es casi lo único imprescindible para que haya composición escrita funcional, sentida (Rincón et al., 1999, p. 68-69)

Desafortunadamente, algunas docentes de preescolar han dejado de lado el interés del niño(a) y tomado el concepto de escritura como una estética, pues solo piensan en el modo de la letra, que sea bien redonda, que no sea muy grande pero tampoco muy pequeña, utilizando como recurso la elaboración de muchas planas para ir perfeccionando la escritura de las letras, lo cual no tiene sentido para los niñs(as). La implementación de este mal recurso genera desmotivación y por ende hace que los niños y niñas pierdan el interés total por la escritura. Es claro que los niños no aprenden a escribir a través de planas y planas:

Mientras el niño considera que la escritura tiene un sentido, en la enseñanza escolar predominan los métodos que parten de elementos menores que la palabra (Ilamados "sintéticos") o que van desde la palabra a la frase (Ilamados "analíticos"), es decir, de partes de textos, pero no de textos, entendiendo éstos no como aquel escrito que tenga tal número de oraciones o párrafos, sino como producciones de significación globales como un cuento, una lista, una propaganda, un grito de auxilio (Rincón et al., 1999, p. 14-15).

Cabe resaltar que además de seguir fragmentando el lenguaje escrito debido a la utilización de métodos poco favorables para el niño(a), también se continúa haciendo a un lado el aprendizaje basado en los conocimientos previos de cada uno(a) y lo más importante, la verdadera intención comunicativa que cada individualidad busca transmitir a través de la lengua escrita. Por ello se evidencian aún hoy, en muchas instituciones educativas para la infancia, experiencias poco amables y productivas: 
Hasta ahora ha sido costumbre iniciar la enseñanza de la escritura con el entrenamiento de habilidades manuales. Bajo la denominación de aprestamiento o de preescritura, se trabaja en el entrenamiento de la mano, la direccionalidad y se sigue con las vocales, lo cual, en ocasiones, se hace de manera insistente y repetida durante muchos de los años en que los niños y niñas están en el jardín infantil.

Con lápices, con cantos, con colores, con el cuerpo, corriendo, en arena, en harina y, hasta tocándolas en papel de lija, se la pasan en una procesión eterna, hasta que un buen día, en transición, llega la señora " $m$ " y se junta con la "a" dando origen al "ma, me, mi, mo, mu" y toda la parafernalia de "memo ama a mi mamá" y "mi mamá me mima". Comienza así formalmente la enseñanza del código alfabético. De esta manera se alfabetiza al niño, es decir, se le enseña a trazar letras y a formar con ellas palabras, pero no se le enseña el lenguaje escrito (Negret, 2005: 9).

Por lo anterior,el lenguaje escrito pierde su valor y su esencia, es decir, la posibilidad de comunicar las experiencias, emociones, gustos, deseos, o simplemente el querer transmitir sus pensamientos a los demás, para alcanzar la interacción con el mundo que nos rodea. Al pensar que tan alto es el sentido de comunicarnos, es satisfactorio también pensar en los sistemas de comunicación que establece el niño dentro del aula.

\section{La escritura "herramienta mágica para el niño(a)"}

Si se dice que la escritura es la posibilidad de ser y construir a partir de la magia de la palabra, esto implica reconocer que el niño también tiene esa posibilidad de crear, de transformar, de construir a partir de sus vivencias, de lo que cree, y también, a partir de sus errores:

De un error puede nacer una historia, no hay en ello ninguna novedad. $\mathrm{Si}$, al pasar a máquina un artículo, resulta que escribo "Cocombia" en lugar de "Colombia", he descubierto un país nuevo, sabroso y silvestre: sería una lástima sacarlo de los mapas de lo posible por medio de un borrador especial; mejor explorarlo, como turistas de la fantasía (Rodari, 1999: 48).

Según Rodari los errores en los niños(as) deben verse como posibilidades de desarrollo en el proceso escritor y no como dificultades, como visibilizan estos errores algún@s docentes, llevando a veces a pedir una valoración de los niños(as) para buscar soluciones en donde no hay problemas.

Recordemos que el lenguaje escrito está constantemente en el entorno de los niños,(as) y es observable, ya que está presente en avisos, envases de productos que utilizan habitualmente, además, al observar que los adultos escriben cartas, notas, entre otras producciones, se despierta en ellos un gran interés sobre el lenguaje escrito. En este momento, es cuando el niño(a) empieza a buscar la forma de representar mensajes, ideas, etc., a partir de las concepciones que ha logrado construir de la lengua escrita. 
El reto de formar lectores y escritores desde la infancia: una realidad que va más allá del aula | Emilse Carolina Cifuentes Cetina | Johanna González Aguilera | Deivis Solangel Morales Reinoso |

Por tal motivo, se hace evidente la importancia de adquirir el código alfabético, pero este no se logra de la noche a la mañana, ni por arte de magia y tampoco a la fuerza, y aunque no se maneje el código, sí se poseen unas habilidades innatas que son las que hacen más fácil el alcance del mismo, las cuales se nutren de la motivación y el interés en la infancia.

Además, si se dice que a través de la escritura los seres humanos expresan sentimientos, estados de ánimo y dan a conocer sus necesidades, es importante cultivar y motivar desde la infancia este proceso, y para ello es necesario contar con el apoyo de los padres. En casa, no se deben cortar las alas de la imaginación a los niños(as), por el contrario, los padres deben motivar y enriquecer estas experiencias, para ello, puede ser de gran ayuda una muy buena intervención de la maestra, quien puede brindar pautas de cómo llevar a cabo el proceso escritor en casa de manera provechosa y amena:

Con las historias y los procedimientos fantásticos para producirlas, nosotros ayudamos a los niños a entrar en la realidad por la ventana, en vez de hacerlo por la puerta. Es más divertido, y por lo tanto más útil (Rodari, 1999, p. 43).

En esta instancia se hace imperioso creer en la infancia y en su potencial innovador a nivel escritural desde su percepción del mundo, esta etapa es la más provechosa y por ende es necesario desarrollar múltiples estrategias que permitan el goce y fortalecimiento del proceso escritor a través de la realización de actividades verdaderamente significativas, en donde el niño(a) construya sin temor a equivocarse, pues si cree en él, se formará como el escritor de su propia vida, en la que es y será el protagonista de miles y miles de hazañas.

\section{Posición de la pedagoga infantil y su reto de formar lectores y escritores desde la infancia}

Para cambiar la realidad y demostrar la importancia de la escritura y la lectura en la infancia, la pedagoga infantil debe ser en todo momento un sujeto activo y facilitador de experiencias enriquecedoras para desarrollar el proceso lector y escritor de los niños (as) en el aula y fuera de ella, no se puede seguir pensando que la escritura y la lectura son herramientas utilizadas únicamente en la escuela, se debe cambiar el paradigma y devolverle a estas poderosas herramientas su valor y sentido cultural, reconociendo que los niños poseen habilidades de lectura y escritura mucho antes de entrar al jardín, pues las han adquirido mediante su relación con los demás y en el contexto sociocultural que le rodea, aún antes de nacer.

Por tal motivo es evidente que la pedagoga infantil no debe realizar un aprestamiento para la lectura y la escritura, debe enriquecer el proceso de cada niño(a) a partir de sus intereses y motivaciones, a partir de su realidad, de su mundo 
y de sus expectativas. El niño(a) es creador todo el tiempo y busca siempre los medios y el espacio para inventar sus historias.

La pedagoga infantil para formar el hábito de lector y escritor debe dar ejemplo a los niños(as) al hacer lecturas de manera armoniosa y al promover la escritura buscando intenciones comunicativas afines a los intereses de los niños(as) a cada instante, debe hacer del tiempo de lectura y escritura el mejor momento para pensar, sentir y crear. Se debe resaltar siempre el rol del pedagoga infantil, pues gracias a su intervención se generarán grandes logros:

Ese espacio privilegiado del salón de clase podrá ser principio de futuros autores, escritores, artistas, si nosotros, los educadores, hacemos de la literatura infantil un momento de placer, donde el alumno sienta gusto en leer una historia y no como una tarea más a cumplir (Oliveira, 1994, p.12).

Como conclusión, la lectura y la escritura permiten al niño(a) hacer evidente gran infinidad de experiencias adquiridas en el entorno, por consiguiente, se debe establecer un vínculo entre la necesidad y la motivación para comunicar, expresar sentimientos, emociones, situaciones y vivencias que son de gran interés para ellos(as). Por otro lado, se hace indudable que estas dos herramientas forman parte del desarrollo cultural del niño(a) y la pedagoga infantil, como la familia deben ser potenciadoras de las mismas.

No se puede olvidar que del adulto, tanto del pedagogo como del padre de familia depende el buen proceso lector-escritor de la infancia y por ende de la sociedad.

No se debe escatimar en estrategias ni recursos para lograr el propósito de formar lectores y escritores para la vida.

Así como un sistema humano de atención a la infancia no es una sala de cunas y comedores, los jardines infantiles no son acuarios. Es claro que los niños están en total capacidad de desarrollar los lenguajes y los pensamientos de la cultura.

Juan Carlos Negret 
El reto de formar lectores y escritores desde la infancia: una realidad que va más allá del aula | Emilse Carolina Cifuentes Cetina | Johanna González Aguilera | Deivis Solangel Morales Reinoso |

\section{Referencias}

De Oliveira, M.A. (1994). Dinámicas de literatura infantil. Bogotá, Colombia: San Pablo.

Negret, J.C. (2005). La escritura antes de la escritura. Bogotá: Colombia: Herramientas y Gestión.

Rincón, B.G. (1999). La enseñanza de la lengua escrita y de la lectura. Bogotá: Colombia: Arango editores.

Rodari, G. (1999). Gramática de la fantasía. Bogotá: Colombia: Panamericana. 